\title{
Cone-beam computed tomographic evaluation of severely curved canals instrumented with ProTaper Next, WaveOne, and OneShape file systems
}

\author{
Ersan Çiçek, ${ }^{1}$ Mustafa Murat Koçak, ${ }^{1}$ Sibel Koçak, ${ }^{1}$ Baran Can Sağlam, ${ }^{1}$ Murat Iç̧en ${ }^{2}$ \\ 'Department of Endodontics, Faculty of Dentistry, Bülent Ecevit University, Zonguldak, Turkey \\ ${ }^{2}$ Department of Oral Radiology, Faculty of Dentistry Bülent Ecevit University, Zonguldak, Turkey
}

\begin{abstract}
Objective: In this study, three NiTi systems were compared in terms of the changes in canal curvature in both mesiodistal (MD) and buccolingual (BL) directions by cone-beam computed tomographic (CBCT) imaging.

Methods: Mesiobuccal canals of 48 extracted human mandibular molar teeth with severely curved roots $\left(32^{\circ}-52^{\circ}\right)$ were used. The teeth were randomly divided into three groups as follows; group1: WaveOne primary, group 2: OneShape, and group 3: ProTaper Next. The canals were instrumented to a master apical file size of \#25 in each group. Preinstrumentation root canal curvatures were obtained by using $C B C T$ images. The root canal curvature of each tooth was recorded. After the instrumentation, postinstrumentation CBCT images were obtained with the same method. Pre-and-postinstrumentation $\mathrm{CBCT}$ images were analyzed by using ImageJ software. Differences among the groups were analyzed by one way analysis of variance (ANOVA) or the Kruskal-Wallis test.
\end{abstract}

Results: No difference was found among three instrumentation systems ( $p>0.05)$.

Conclusion: Although all instruments demonstrated changes in root canal curvatures and straightened the root canals, these changes and straightenings may be inconsiderable in clinical conditions.

Keywords: CBCT imaging; severely curved canal; root canal straightening; NiTi instruments.

The aim of root canal instrumentation is to remove the organic and inorganic contents of root canal system, to shape the whole root canal by keeping the original geometry. The mechanical instrumentation of root canal system by endodontic instruments is crucial step to achieve success in root canal treatment. Various instruments and instrumentation techniques have been proposed for cleaning and shaping of the root canal system efficiently while keeping the original root canal anatomy. However, none of the instru- ments or techniques could completely challange the occurance of ledge formation, canal straightening, and canal transportation of apical foramen or even perforation during mechanical instrumentation. ${ }^{[1-4]}$ Additionally, the possibility of such complications increase as a result of complex root canal anatomy in curved canals.

The use of rotary nickel-titanium (NiTi) instruments allows easier and safer root canal shaping with predictable results. ${ }^{[5]} \mathrm{NiTi}$ instruments tend to be more centered, rap-

Correspondence: Ersan ÇiçEK, Bülent Ecevit University, Faculty of Dentistry, Depertmant of Endodontics, Zonguldak/TURKEY

Tel: +90 372 - 2613413 Fax: +0903722613403 e-mail: ersancicek@beun.edu.tr

Submitted: January 13, 2015 Accepted: April 06, 2015 
id, and attain a more conservative shaping of canals than stainless steel instruments. ${ }^{[6]}$

Recently, various instruments and instrumentation techniques have been introduced to achieve a better instrumented root canal. The use of endodontic files in a reciprocating motion, and new manufacturing processes have been introduced. ${ }^{[7]}$ The WaveOne file (WO; Dentsply Maillefer, Ballaigues, Switzerland) is made of M-wire NiTi alloy which is used in a reciprocating motion. In contrast, the OneShape file(OS;Micro-Mega ${ }^{\circledR}$, Besançon, France) ismadeofaconventional austenite $55-\mathrm{NiTi}$ alloy and is used in a full clockwise rotation motion. ${ }^{[8]} \mathrm{A}$ recently introduced $\mathrm{M}$-wire alloy, ProTaper Next system (PTN; Dentsply Tulsa Dental Specialties/ Dentsply Maillefer), includes various tapers on a single file with the offset design. An offset design generates a travelling mechanical wave of motion along the active portion of a file. This swaggering effect serves to minimize the engagement between the file and dentin compared to the action of a fixed tapered file with a centered mass of rotation. Reduced engagement limits any undesirable taper lock, the screw effect, and the torque on any given file. ${ }^{[9]}$

The aim of the present study was to compare three NiTi (the WaveOne file, OneShape file, the ProTaper Next system) systems in terms of the changes in canal curvature in both mesiodistal (MD) and buccolingual (BL) directions in severely curved root canals. The null hypothesis tested was that there is no difference among the three NiTi systems regarding their effect on root canal straightening in severely curved root canals.

\section{Materials and methods}

In this study, a total of 48 extracted human mandibular molar teeth were selected. Soft tissue and calculus were removed mechanically from the root surfaces. The crowns of teeth were removed from the cementoenamel junction. The root canals were not probed for patency to prevent modification of their apical anatomy.

A hole was created on the cover of the Eppendorf tube, the root was inserted under pressure through this cover and fixed with cyanoacrylate. The tube was fitted into a glass vial for cone-beam computed tomographic (CBCT) imaging (Fig. 1). This set-up was horizontally fitted to a chin support with its occlusal plane parallel to the plate. Preinstrumentation (pre-CBCT) and postinstrumentation (post-CBCT) scans were performed using CBCT; Veraviewepocs 3D R100/F40 (J Morita Mfg. Corp., Kyoto, Japan) and a flat-panel detector with six fields of view (FOVs; Six FOV: $\varnothing 40 \times \mathrm{H} 40 \mathrm{~mm}, \varnothing 40$ x H $80 \mathrm{~mm}, \varnothing 80$ x H $50 \mathrm{~mm}, \varnothing 80$ x H $80 \mathrm{~mm} \mathrm{3D}$ Reuleaux Full Arch FOV: $\varnothing 100$ mm x H 50 mm, Ø 100 $\mathrm{mm} \times \mathrm{H} 80 \mathrm{~mm}$ ). The Veraviewepocs 3D Rl00/F40 was

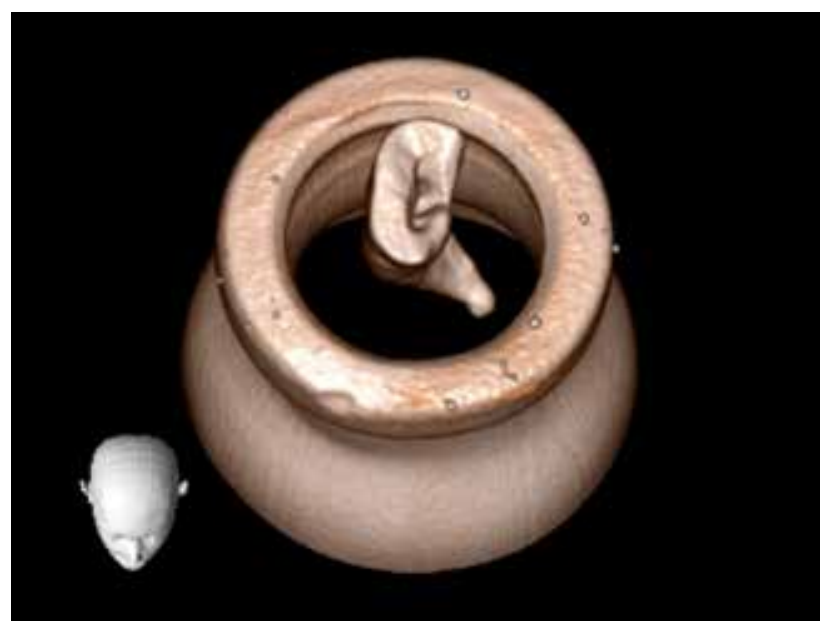

Fig. 1. A CBCT image of set-up including glass vial and root.

used to compare transportation produced by the NiTi systems. All scans were conducted with a $4-\mathrm{cm}$ field of view, at $0.125-\mathrm{mm}$ voxel resolution with $90 \mathrm{kVp}$ and $3 \mathrm{~mA}$. All images were produced in the high-resolution mode. Axial scans and multiplanar reconstructions were obtained, and volumetric data were displayed using the system software to provide serial coronal and sagittal sections along each tooth plane. The images were stored, analyzed, and converted into BMP format with the software provided for the CBCT machine (i-dixel). Three-dimensional CBCT images were acquired before and after the instrumentation from the apical root cross sections located 2, 3, and $4 \mathrm{~mm}$ above the apical foramen. Arithmetic means of measurements obtained from these locations were calculated and evaluated as a single score. The images for each tooth were reconstructed separately.

Following the completion of pre-CBCT imaging, a size 10 stainless steel file was inserted into the root canal until the tip of the instrument was just visible at the apical foramen to determine the working length. The root canal instrumentations were completed in accordance with the recorded working lengths.

The specimens were randomly divided into three groups ( $n=16$ ) according to the NiTi file used for instrumentation. Only MB canals were instrumented. The groups were as follows;

Group 1: WO reciprocating files were used to size Primary Reciprocating File 025 (.08 taper, $25 \mathrm{~mm}$ ). The files were used with an endodontic motor (WaveOne motor, Dentsply Maillefer, Ballaigues, Switzerland) and operated with a $6: 1$ reducing handpiece. The pre-programmed motor was set for the angles of reciprocation and the speed for WaveOne instruments according to manufacturer's instructions. The files were used with a progressive up-anddown movement no more than three to four times with a 
Table 1. The mean difference between pre- and postinstrumented canal curvatures

\begin{tabular}{llcc} 
Direction & Group & Mean \pm SD $\left({ }^{\circ}\right)$ & Min.- Max. $\left({ }^{\circ}\right)$ \\
\hline Buccolingual & WaveOne & $5.51 \pm 2.47^{\mathrm{a}}$ & $2.18-10.49$ \\
& OneShape & $5.70 \pm 2.57^{\mathrm{a}}$ & $2.12-11.13$ \\
\multirow{3}{*}{ Mesiodistal } & ProTaper Next & $5.49 \pm 2.31^{\mathrm{a}}$ & $2.21-9.80$ \\
& WaveOne & $0.35 \pm 0.18^{\mathrm{b}}$ & $0.07-0.70$ \\
& OneShape & $0.32 \pm 0.17^{\mathrm{b}}$ & $0.05-0.70$ \\
& ProTaper Next & $0.34 \pm 0.14^{\mathrm{b}}$ & $0.15-0.60$ \\
\hline
\end{tabular}

*Same letters in the column indicate the differences are not significant ( $p>.05)$.

minimal apical pressure. The files were then removed and wiped clean. The same procedure was repeated until the file reached the working length (WL).

Group 2: A size 25 OS file with a taper of .06 in a rotating motion was used in a 16:1 gear reduction handpiece powered by a torque-controlled electric motor (XSmart Europe; Dentsply, Japan) at a consistent rotation of $400 \mathrm{rpm}$. The torque was adjusted to $4 \mathrm{Ncm}$ according to the manufacturer's instructions.

Group 3: PTN system was used with the following sequence at $300 \mathrm{rpm}$ for instrumentation of the root canals, $\mathrm{X} 1$ and X2 were used up to working length. The X2 file corresponds to file 25 with a taper .06 at the apical area.

After the root canal instrumentation, post-CBCT scans were performed by using the same method as described for the pre-CBCT analysis. The pre- and post-CBCT images were exported to ImageJ 1.47 software (National Institutes of Health, Bethesda, MD) to determine the straightening of the canal curvature by using the method which was previously described. ${ }^{[10]}$ Two semistraight lines of equal length were created. The first line represented the continuity of the apical region and the second line followed the middle and coronal thirds of the root canal. The midpoints of each line were determined and a circle was drawn to pass over the midpoints. The center of the circle was marked and two lines representing the radius ( $r$ ) were drawn to the midpoints. The magnitude of the curve was determined geometrically $(\alpha)$ and the canal curvature was expressed in degrees $\left({ }^{\circ}\right)$ (Figs. 2a and b).

Statistical analysis was performed with SPSS 18.0 software (SPSS Inc., Chicago, IL, USA). Results were expressed as mean \pm std. deviation. Differences among the groups were analyzed by one way analysis of variance (ANOVA) or the Kruskal-Wallis test. Pearson's or Spearman's correlation analysis was performed to determine the relationship between continuous variables. $P$ value of less than 0.05 was considered statistically significant for all tests.

\section{Results}

The 48 canals showed $\mathrm{BL}$ and $\mathrm{MD}$ curvatures ranging from 32.7 to $52.2^{\circ}$ and 10.7 to $19.4^{\circ}$, respectively. All instruments demonstrated some changes in terms of canal curvature in both $\mathrm{BL}$ and $\mathrm{MD}$ directions. The initial mean BL curvatures of teeth in groupl, group 2, and group 3 were $42.33,42.86$, and 42.51 , respectively. No difference was found between the curvature changes after instrumentation in $\mathrm{BL}$ direction $(\mathrm{p}>.05)$ (Table $\mathrm{l})$. The initial mean $\mathrm{MD}$ curvatures of teeth in groupl, group 2, and group
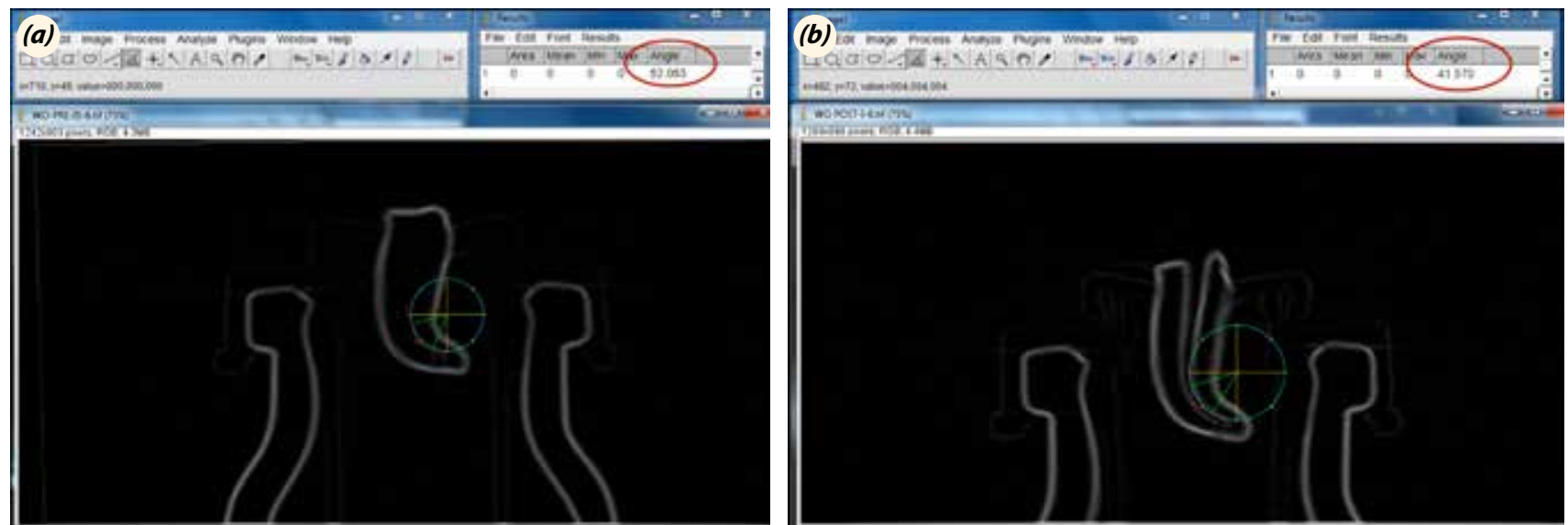

Fig. 2. (a) A sample of preinstrumentation root canal curvature measurement. (b) A sample of postinstrumentation root canal curvature measurement. 
3 were $15.18^{\circ}, 15.06^{\circ}$, and $15.59^{\circ}$, respectively. In MD direction, there was no significant difference among the 3 groups in terms of canal straightening after the instrumentation ( $\mathrm{p}>.05)$ (Table 1). No instrument fracture occured during the instrumentation of root canals.

\section{Discussion}

Various tomography devices were used in the past to determine the changes in root canal geometry. However, CBCT images provide a $0.125-\mathrm{mm}$ thickness of voxel resolution that result in detailed evaluation when compared to 0.6mm thick axiel sections provided by hrCT. ${ }^{[4]} \mathrm{CBCT}$ requires additional software applications which are widely available and include Adobe Photoshop and ImageJ. ${ }^{[11,12]}$ Wenzel et al. ${ }^{[13]}$ reported that image enhancement could be performed to improve the sensitivity of high resolution CBCT images. Özer ${ }^{[4]}$ stated that the enhancement of CBCT images with software allowed a detailed investigation of the instrumentation of curved root canals. In the present study, the enhancement of pre- and post-CBCT images was performed by ImageJ software for a detailed investigation taking the previous suggestions into account.

The variables of this study were; alloy of instruments, different kinematics of instruments (reciprocation-rotation), number of files (single file-full sequence file), and the design of files (taper of files, and constant-progressive and regressive taper). No significant difference was found among the changes in root canal curvature after the instrumentation in both BLand MD directions. Although the findings in the BL direction were in agreement with the results of previous studies, ${ }^{[8,14-16]}$ the canal curvature changes in MD direction could not be compared due to the absence of previously published data. A root canal demonstrates curvatures in both MD and BL directions. Therefore, the present study aims to contribute to the literature.

In the present study, the changes in the canal curvatures were not statistically significant which was in agreement with the previous findings. ${ }^{[8,14-17]}$ This similarity could be related to the instruments which work with less apical pressure and conserve the initial anatomy of curved root canals owing to their non-cutting tips. ${ }^{[18]}$ However, Schäfer ${ }^{[19]}$ reported that non cutting tips could produce transportation in severely curved canals. Therefore, in this study, mesial roots of mandibular molars were selected due to the fact that these roots are commonly narrow and suddenly curved in two planes increasing the level of instrumentation difficulty. ${ }^{[20,21]}$

The standardization of the master apical file is essential to compare the shaping ability of different instrumentation systems. Thus, the final apical instrumentation was completed with a size 25 in all groups. For single file sys- tems, WO and OS were selected and for full-sequence file system PTN was selected. Berutti et al. ${ }^{[22]}$ reported that the canal length significantly decreased after instrumentation of WO due to the straightening of root canal curvature. Moreover, Saber et al. ${ }^{[23]}$ stated that the curved root canals were also straightened after OS instrumentation and this straightening was higher than WO instrumentation. Similarly, in the present study the curved root canals were straightened after $\mathrm{WO}$ and OS instrumentation and the most curvature changes were observed in OS group without any significance. The lowest curvature changes were obtained in PTN group, but there was no significant difference among the three groups. The difference could be related to the facts below;

1- Alloy: WO and PTN instruments are made of Mwire technology, whereas OS is made of conventional martensitic NiTi. Shen et al. ${ }^{[24]}$ stated that M-wire NiTi has more superior flexibility than conventional NiTi. Furthermore, M-wire NiTi instruments had more flexibility and fatigue resistant than the conventional NiTi instruments. ${ }^{[9,25-27]}$

2- Kinematics: WO was used in reciprocation motion which is associated with well-centered instrumentation and decreased procedural errors. ${ }^{[7,28]} \mathrm{WO}$ works in a reciprocating movement similar to the balanced force technique. ${ }^{[2]}$ The reciprocating movement minimizes torsional and flexural stresses ${ }^{[29]}$ and reduces canal transportation..$^{[2,7,28]}$

3- File designs: WO has variable cross-sections along the working part that change from a concave triangular crosssection with radial land at the tip to neutral rake angle with triangular convex cross-section in the middle part and near the shaft. ${ }^{[18,23]}$ The radial lands in combination with the reciprocation motion are claimed to keep the WO centered whilst advancing apically into the root canal. ${ }^{[23,29]}$ OS has a variable 3 -cutting edge design at the tip resion that progressively changes from 3 to 2 cutting edges in the middle part, whereas near the shaft, the instrument has 2 cutting edges. ${ }^{\left[{ }^{[23]}\right.}$ This design used in continuous rotation at a relatively higher speed allows the instruments to rapidly progress into the curved root canals. This could create some stress that might result in the observed canal straightening. PTN has progressive and regressive percentages taper. This could allow the instrument to move with a snake-like swaggering into the root canals. The manufacturer claims that this rotation of the cross-section creates the enlarged space for removing debris (Protaper Next, direction for use).

Our results are in agreement with several previous studies..$^{[8,23,27,29]}$ Bürklein et al. ${ }^{[8,18]}$ and Capar et al. ${ }^{[17]}$ stated that WO and OS maintained the original canal curvature of severely curved canals in extracted human teeth. 
Additionally, Capar et al. ${ }^{[17]}$ reported that there was no significant difference in terms of canal curvature straightening after instrumentation with WO, OS and PTN instruments. Previous results demonstrated that the changes in canal curvature after instrumentation with $\mathrm{WO}, \mathrm{OS}$, and PTN were $3.87^{\circ}, 4.90^{\circ}$, and $3.76^{\circ}$, respectively. ${ }^{[17]}$ Our results demonstrated slightly higher amount of changes in curvature which could be related to the selection of teeth with higher canal curvatures in the present study $\left(32^{\circ}-\right.$ $52^{\circ}$ ). Thus, we may conclude that the increase in canal curvature results in higher amount of changes during the instrumentation.

\section{Conclusions}

Although all instruments resulted in changes in root canal curvatures and straightened the root canals, these changes and straightenings may be inconsiderable in clinical conditions. Moreover, three instruments kept the main root canal anatomy relatively and maintained the original canal curvature, as well.

Conflicts of Interest: No conflicts declared.

\section{References}

1. Weine FS, Kelly RF, Bray KE. Effect of preparation with endodontic handpieces on original canal shape. J Endod 1976;2:298,303.

2. Roane JB, Sabala CL, Duncanson MG Jr. The "balanced force" concept for instrumentation of curved canals. J Endod 1985;11:203-11.

3. Hülsmann M, Schade M, Schäfers F. A comparative study of root canal preparation with HERO 642 and Quantec SC rotary Ni-Ti instruments. Int Endod J 2001;34:53846.

4. Özer SY. Comparison of root canal transportation induced by three rotary systems with noncutting tips using computed tomography. Oral Surg Oral Med Oral Pathol Oral Radiol Endod 2011;111:244-50.

5. Giannastasio D, Rosa RA, Peres BU, Barreto MS, Dotto GN, Kuga MC, et al. Wizard CD Plus and ProTaper Universal: analysis of apical transportation using new software. J Appl Oral Sci 2013;21:468-74.

6. Kum KY, Spängberg L, Cha BY, Il-Young J, Msd, SeungJong $L$, et al. Shaping ability of three ProFile rotary instrumentation techniques in simulated resin root canals. J En$\operatorname{dod} 2000 ; 26: 719-23$.

7. Franco V, Fabiani C, Taschieri S, Malentacca A, Bortolin M, Del Fabbro M. Investigation on the shaping ability of nickel-titanium files when used with a reciprocating motion. J Endod 2011;37:1398-401.

8. Bürklein S, Benten S, Schäfer E. Shaping ability of different single-file systems in severely curved root canals of ex- tracted teeth. Int Endod J 2013;46:590-7.

9. Haapasalo M, Shen Y. Evolution of nickel-titanium instruments: from past to future. Endodontic Topics 2013;29:3-17.

10. Estrela C, Bueno MR, Sousa-Neto MD, Pécora JD. Method for determination of root curvature radius using cone-beam computed tomography images. Braz Dent J 2008; 19:114-8.

11. Hartmann MS, Barletta FB, Camargo Fontanella VR, Vanni JR. Canal transportation after root canal instrumentation: a comparative study with computed tomography. J Endod 2007;33:962-5.

12. Bernardes RA, Rocha EA, Duarte MA, Vivan RR, de Moraes IG, Bramante AS, et al. Root canal area increase promoted by the EndoSequence and ProTaper systems: comparison by computed tomography. J Endod 2010;36:1179-82.

13. Wenzel A, Haiter-Neto F, Frydenberg M, Kirkevang LL. Variable-resolution cone-beam computerized tomography with enhancement filtration compared with intraoral photostimulable phosphor radiography in detection of transverse root fractures in an in vitro model. Oral Surg Oral Med Oral Pathol Oral Radiol Endod 2009;108:939-45.

14. Celik D, Taşdemir T, Er K. Comparative study of 6 rotary nickel-titanium systems and hand instrumentation for root canal preparation in severely curved root canals of extracted teeth. J Endod 2013;39:278-82.

15. Marzouk AM, Ghoneim AG. Computed tomographic evaluation of canal shape instrumented by different kinematics rotary nickel-titanium systems. J Endod 2013;39:906-9.

16. You SY, Kim HC, Bae KS, Baek SH, Kum KY, Lee W. Shaping ability of reciprocating motion in curved root canals: a comparative study with micro-computed tomography. J Endod 2011;37:1296-300.

17. Capar ID, Ertas H, Ok E, Arslan H, Ertas ET. Comparative study of different novel nickel-titanium rotary systems for root canal preparation in severely curved root canals. J Endod 2014;40:852-6.

18. Bürklein S, Hinschitza K, Dammaschke T, Schäfer E. Shaping ability and cleaning effectiveness of two single-file systems in severely curved root canals of extracted teeth: Reciproc and WaveOne versus Mtwo and ProTaper. Int Endod J 2012;45:449-61.

19. Schäfer E. Effect of four instrumentation techniques on curved canals: a comparison study. J Endod 1996;22:68590.

20. Berutti E, Fedon G. Thickness of cementum/dentin in mesial roots of mandibular first molars. J Endod 1992;18:545-8.

21. Gergi R, Osta N, Bourbouze G, Zgheib C, Arbab-Chirani $R$, Naaman A. Effects of three nickel titanium instrument systems on root canal geometry assessed by micro-computed tomography. Int Endod J 2015;48:162-70. 
22. Berutti E, Chiandussi G, Paolino DS, Scotti N, Cantatore $\mathrm{G}$, Castellucci A, et al. Effect of canal length and curvature on working length alteration with WaveOne reciprocating files. J Endod 2011;37:1687-90.

23. Saber SE, Nagy MM, Schäfer E. Comparative evaluation of the shaping ability of WaveOne, Reciproc and OneShape single-file systems in severely curved root canals of extracted teeth. Int Endod J 2015;48:109-14.

24. Shen Y, Cheung GS, Bian Z, Peng B. Comparison of defects in ProFile and ProTaper systems after clinical use. J Endod 2006;32:61-5.

25. Pereira ES, Peixoto IF, Viana AC, Oliveira II, Gonzalez $\mathrm{BM}$, Buono VT, et al. Physical and mechanical properties of a thermomechanically treated NiTi wire used in the manufacture of rotary endodontic instruments. Int Endod J 2012;45:469-74.
26. Alapati SB, Brantley WA, Iijima M, Clark WA, Kovarik L, Buie C, et al. Metallurgical characterization of a new nickel-titanium wire for rotary endodontic instruments. J Endod 2009;35:1589-93.

27. Zhao D, Shen Y, Peng B, Haapasalo M. Micro-computed tomography evaluation of the preparation of mesiobuccal root canals in maxillary first molars with Hyflex CM, Twisted Files, and K3 instruments. J Endod 2013;39:3858.

28. Varela-Patiño P, Ibañez-Párraga A, Rivas-Mundiña B, Cantatore G, Otero XL, Martin-Biedma B. Alternating versus continuous rotation: a comparative study of the effect on instrument life. J Endod 2010;36:157-9.

29. Webber J, Machtou P, Pertot W, Kutler S, Ruddle C, West J. The WaveOne single file reciprocating system. Roots 2011;7:28-33. 